\title{
Predictions of Overbreak Blocks in Tunnels Based on the Wavelet Neural Network Method and the Geological Statistics Theory
}

\author{
Sun Shaorui, Liu Jiaming, and Wei Jihong \\ College of Earth Science and Engineering, Hohai University, Nanjing, Jiangsu 210098, China \\ Correspondence should be addressed to Sun Shaorui; ssrfish@hhu.edu.cn
}

Received 8 November 2012; Revised 6 February 2013; Accepted 6 February 2013

Academic Editor: Tsung-Chih Lin

Copyright (C) 2013 Sun Shaorui et al. This is an open access article distributed under the Creative Commons Attribution License, which permits unrestricted use, distribution, and reproduction in any medium, provided the original work is properly cited.

Predicting overbreak blocks is a valid way to protect constructors, safeties in the process of tunnel excavation. In this paper, a prediction method of the overbreak blocks in tunnels is developed in the frame of the wavelet neural network of geological statistics models. Geometrical parameters of structural plane are first obtained by field survey. Then, a statistical model can be deduced from the measured geometrical parameters on the basis of the geological statistics theory. Furthermore, the volumes and distribution of the overbreak blocks are calculated by the theory of wavelet neural network. Finally, the valid support measurements can be designed according to the prediction results for all overbreak blocks appeared in tunnel excavation, and the amount of overbreak blocks can also be predicted. The code with respect to the method has been developed by the fortran language. The method proposed in this paper has been used in a tunnel construction. The results show that there exists an approximate $10 \% \sim 30 \%$ difference between the prediction and the real volume of overbreak blocks. Therefore, the method can be well used to predict the volumes distribution and the overbreak blocks, and the accordingly support measurements can be also given according to the prediction results.

\section{Introduction}

Tunnel excavation is the most common technique in hydropower engineering, traffic engineering, mineral engineering, and so forth. Therefore, a method which can validly predict potential danger would be of significant benefit to the tunnel construction operators, since the tunnel excavation has been the most common construction activity.

In recent years, undesirable surrounding rock collapses frequently arose in tunnel excavation, which often lead to casualty. Therefore, it is urgent to develop a valid and convenient method to predict potential danger in tunnel excavation. Jimin and Mahtab [1] obtained the sizes, shapes, and locations of overbreak blocks by structural plane geometrical characteristics in the case of underground tunnels; Jiamei et al. [2] analyzed the effects of surrounding rock and support structure stability by TBM excavation from the angle of quantity; Jian and Xinjiao [3] deduced the statistical regularity of overbreak block sizes and locations in expressway tunnels; Deyun [4] proposed a calculation method of the areas of overbreak and underbreak blocks from the view of mathematics; Huibing [5] applied the drill hole blasting method to seek overbreak and underbreak block sizes and locations; Mingnian and Baoshu [6] used the self-adaption finite element method to analyze the effects of tunnel overbreak blocks on stability of surrounding rock; Revey [7] proposed a control overbreak method of mine tunnel by means of control blasting; Ibarra et al. [8-10] proposed a light-section method to evaluate the volumes of overbreak blocks and developed the relevant equipment and calculation program; Thidemann [11], Abel [12], and Martna [13] applied numerical method to analyze the interaction of tunnel overbreak blocks and surrounding rock deformation. In fact, overbreak blocks in tunnel excavation arise from two aspects: incorrect excavation and natural structural plane. However, the above-mentioned forecasting and evaluation methods only focus on the excavation factor. Goodman [14] put forward the block theory (BT), which can reflect the effect of natural structural plane on overbreak blocks. However, only specific structural plane can be considered in BT. Stochastic 
distribution of structural-plane-induced overbreak has not been well understood. As a result, the method accurate and high calculation efficiency could not be satisfied.

In this paper, a new method, which can reflect stochastic distribution of structural-plane-induced overbreak, is introduced. The wavelet neural network theory is employed to predict overbreak blocks in tunnel excavation. Due to the time domain localization of wavelet translation and self-study function of ordinary neural networks, this method possesses powerful approximation and fault-tolerant capacities.

\section{Prediction Methods and Theories of Overbreak Blocks}

\subsection{Geometrical Parameter Statistical Theory of Structural} Plane. After the large quantity data collected from field survey was statistically analyzed, the structural plane geometrical parameter models of rock masses were constructed by adopting statistical theory. Previous geological data were processed by using the conventional arithmetical method. Due to the fact that the geological parameters were collected from limited field outcrops, it was apparently shown that the variable parameters would lead to erratic results. Thus, it was important to gather the rational geometrical parameters by using limited geological data. The structural plane statistics model theory is a suitable theory for such a work due to successfully obtaining proper parameters based on the limited field data.

The adopted geometrical parameters include the following characteristics: the orientation of structural plane, the trace length of structural plane, and the spacing of the structural plane are statistic, and the mean value and variance of geometrical parameters are obtained. According to the distributed characteristics, the mathematical expectation and variance are gained via the geometrical parameter model, then the confidence interval of every geometrical parameter is determined. The input parameters of the wavelet neural network are obtained from the confidence interval, when the neural network model is used for the prediction of overbreak blocks. Therefore, the calculation parameters are stochastically obtained from their confidence intervals of geometrical parameters.

2.2. Modified Wavelet Neural Network Theory. The wavelet neural network is essential for the proper wavelet bases to be sought from the wavelet characteristic space. The simulation process of the wavelet neural network is realized by iterative calculation of wavelet parameters, which can produce minimal energy. The wavelet neural network is a new feed forward network based on wavelet analysis construction, that is, the nonlinear sigmoid function is substituted by nonlinear wavelet bases. The expression of the network is realized by the linear superimposition of the selected wavelet bases. The expression of network is considered to be a new neural network function of the bases of the wavelet function. Because the time domain localization can be easily identified by wavelet translation, and self-study function can be obtained by means of ordinary neural networks, the

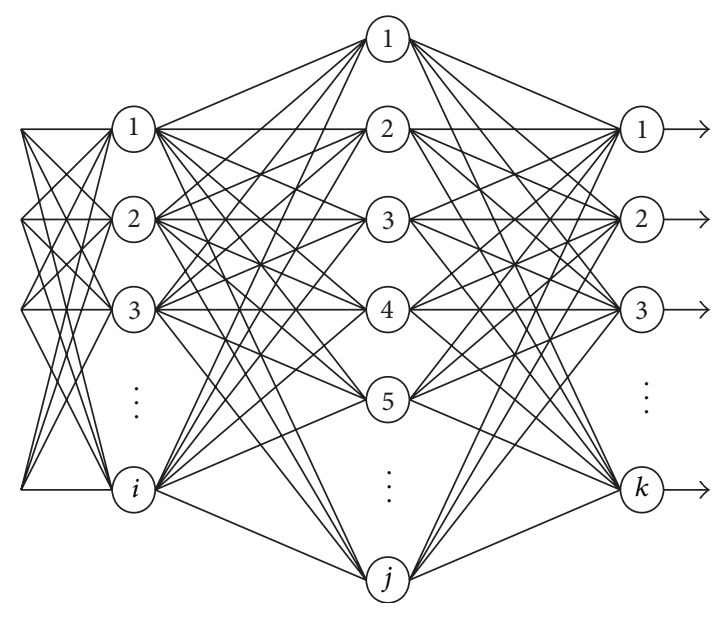

FIGURE 1: Structure of wavelet neural network prediction.

wavelet neural network possesses powerful approximation and fault-tolerant capacities.

The input layer, implication layer nodes, and output layer nodes are defined; the numbers of the implication nodes are the numbers of the wavelet bases function; the output layer is the solution. The structure of network includes three layers as shown in Figure 1.

Using wavelet bases to design and process the network formats the simplified network. The function is a convex function whose minimum value is alone. In this paper, the modified Morlet wavelet, which has the advantages of the calculation stability, low error rate, and strong interference robustness, is adopted. The mother wavelet of the Morlet wavelet can be expressed as follows:

$$
g(x)=\exp \left(-\frac{x^{2}}{2}+j \omega_{0} x\right)
$$

where $j=\sqrt{-1}, \omega_{0} \geq 0$.

The modified Morlet wavelet is as follows:

$$
g(x)=\frac{1}{\sqrt{2 \pi}}\left(i x+\omega_{0}\right) \exp \left(-\frac{x^{2}}{2}+j \omega_{0} x\right) .
$$

Supposing the total number of the input training examples is $P$, the result of output layer is obtained as follows:

$$
f_{a}^{p}=\sum_{k=1}^{K} \omega_{k} \sum_{i=1}^{M} s^{p}\left(x_{i}\right) g\left(\frac{x-b_{k}^{m}}{a_{k}^{n}}\right),
$$

where $M$ is the element number of the input layer; $K$ is The element numbers of implication layer; $\omega_{k}, a_{k}$, and $b_{k}$ are the individual connection weight, translation factor, and dilation factor of the wavelet between the number $k$ element and output node of the implication layer, respectively; and $\mathrm{m}$ and $\mathrm{n}$ are undetermined parameters. The network parameters $\omega_{k}$, $a_{k}$, and $b_{k}$ may be optimized by the energy function:

$$
E=\frac{1}{2} \sum_{p=1}^{P}\left(f_{t}^{p}-f_{a}^{p}\right)^{2}
$$

where $f_{t}^{p}$ is the expectation output of the network, and $f_{a}^{p}$ is the fact output of the network. 


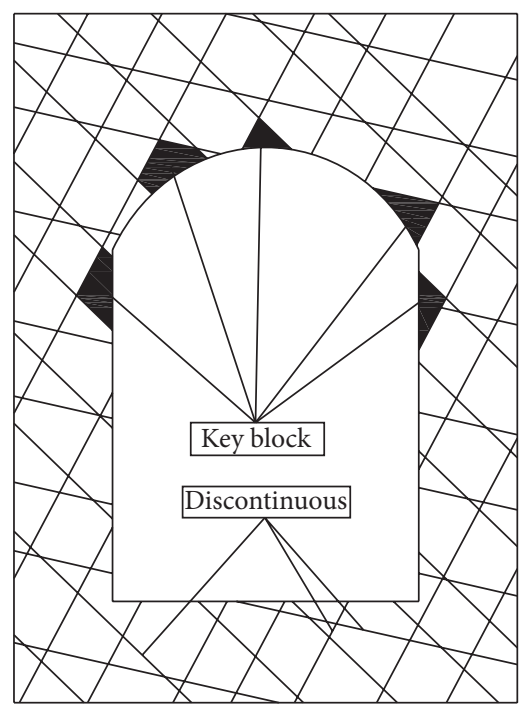

Figure 2: Tunnel overbreak blocks.

2.3. Prediction Method of Overbreak Blocks. The main problems concerning overbreak blocks appear in the tunnel have led to unnecessary excavation due to both geological and man activity influences occurring during tunnel excavation (see Figure 2). The factors that significantly affect the overbreak blocks include (1) natural factors, such as structural plane cutting and geological action and (2) man activity factors, such as excavation methods. At present, the man activity factors have been validly controlled by employing advanced construction methods, such as smoothing blasting and presplitting blasting. So, the natural factors have become the main factors that can significantly affect the overbreak blocks. Partial overbreak blocks in the tunnel may be controlled by analysis and prediction. Therefore, the research concerning overbreak blocks may be used to instruct engineering construction. The related research methods include (1) the geometrical the parameters of the structural plane are defined, (2) the volume range of the overbreak blocks is defined, and (3) the predicted overbreak blocks volume of the tunnel are defined.

\section{Program Design and Wavelet Neural Network Construction}

The calculation program is divided into three parts: the model prediction of geometrical parameters of structural plane, the confidence interval determination, and the wavelet neural network prediction. The parameters are obtained randomly from the confidence interval, and the volume of the overbreak blocks is predicted concerning to the trained network.

\subsection{Model Construction and Confidence Interval Determina-} tion. The models are constructed by adopting mathematical and physical statistics methods. First, the distribution models of the geological geometrical parameters are built. The accepted models must be satisfied by mathematical inspection. According to the parameters of the models, the confidence intervals of satisfying certain confidence levels are defined by statistical methods.

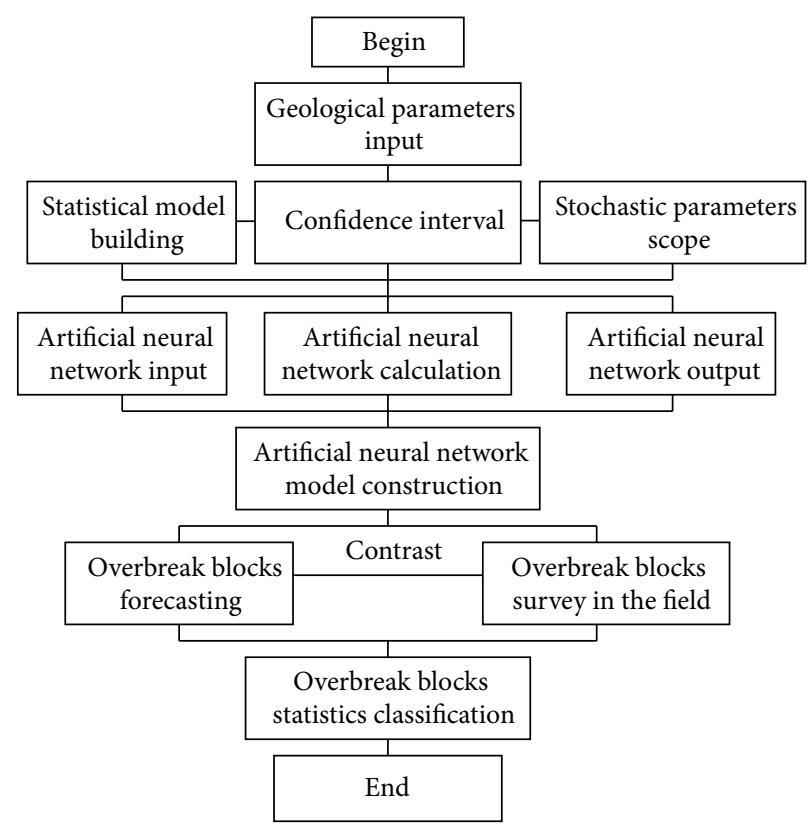

Figure 3: Program flow.

3.2. Training Study of the Wavelet Neural Network. The process of the network training algorithm includes (1) the network parameters, such as $\omega_{k}, a_{k}$, and $b_{k}$, are randomly initialized, (2) the input of study examples and output of expected results, (3) the output results of the network are calculated by using the present network parameters, (4) the parameters of the network increments are calculated, and (5) the study must be terminated when the error is less than the design value; otherwise, the process must begin again from step (3).

3.3. Random Sampling of Parameters. The parameters of the neural network are obtained randomly from the confidence intervals by using random functions.

3.4. Overbreak Blocks Prediction by Trained Network. According to the trained network and geometrical parameters of the structural plane of the tunnel to be predicted, the volume spans of the overbreak blocks occurring in the tunnel are defined by surveying in the field. According to the combination characteristics of different structural planes, the volume spans of the overbreak blocks are divided into four ranges as shown in Table 1.

Figure 3 shows the realization process of overbreak blocks prediction. From the Figure 3, the prediction process includes three phases: model definition of structural plane geometrical parameters, training and building of neural network construction, and tunnel overbreak blocks prediction.

3.5. Certification of Structural Plane Geometrical Parameter Models. Table 2 shows the results of the structural plane geometrical model parameters for tunnel PD6 at Yixing hydropower station located in southern China. In this case, the four parameters of the three groups structural planes are analyzed by employing probability and statistics theories. 
TABLE 1: Volume spans and network outputs of overbreak blocks.

\begin{tabular}{lcccc}
\hline Volume span $/ \mathrm{m}^{3}$ & $>0.5$ & $0.5 \sim 0.1$ & $0.1 \sim 0.05$ & $<0.05$ \\
Network output & $(1,0,0,0)$ & $(0,1,0,0)$ & $(0,0,1,0)$ & $(0,0,0,1)$ \\
\hline
\end{tabular}

TABLE 2: Models of all parameters in tunnel PD6.

\begin{tabular}{|c|c|c|c|c|c|c|}
\hline \multirow{2}{*}{ Parameters of structural plane } & \multirow{2}{*}{ Samples } & \multirow{2}{*}{ Average } & \multirow{2}{*}{ Variance } & \multirow{2}{*}{ Models } & \multicolumn{2}{|c|}{ Parameters of model } \\
\hline & & & & & $a$ & $b$ \\
\hline \multicolumn{7}{|l|}{ Orientation } \\
\hline Joint 1 & 87 & $25.61 / 78.99$ & $15.46 / 65.66$ & \multirow{3}{*}{$\begin{array}{l}\text { Normal model } \\
f(x)=\frac{1}{\sqrt{2 \pi} b} e^{-(x-a)^{2} / 2 b^{2}}\end{array}$} & $25.61 / 78.99$ & $15.46 / 65.66$ \\
\hline Joint 2 & 86 & $55.14 / 67.74$ & $17.34 / 9.62$ & & $55.14 / 67.74$ & $17.34 / 9.62$ \\
\hline Bedding & 45 & $62.96 / 21.33$ & $11.87 / 4.84$ & & $62.96 / 21.33$ & $11.87 / 4.84$ \\
\hline Trace length & 129 & 53.65 & 26.44 & Weibull model & 1.1034 & 0.0225 \\
\hline Spacing & 123 & 18.85 & 11.18 & $f(x)=1-e^{-b x^{a}}$ & 1.689 & 0.0006 \\
\hline
\end{tabular}

Finally, a normal model for the orientation of structural planes and the Weibull model for the trace length and spacing of structural planes are obtained.

Table 3 shows the confidence intervals of different parameters under confidence degrees of $95 \%$ and $99 \%$.

3.6. Wavelet Neural Network Model. Eight input layer nodes, fifteen implication layer nodes, and four output layer nodes are set in the wavelet neural network. In order to observe the network effects, the 21 examples are chosen as study examples of the wavelet neural network. The study efficiency of the network is 0.02 , the error function value is 0.01 , the iteration time is 18390 , and the actual error is $9.9998666 \times 10^{-3}$. Table 4 shows the predicted results of the study examples.

From Table 4, it may be seen that a strong unification exists between the expected outputs and actual outputs. It obviously shows that the results of the network train are positive and that it is capable of assuring prediction accuracy.

\section{Case Study}

4.1. Introduction. The Jinliwen expressway runs through Wenzhou city, Zhejiang province (Figure 4). The double arch tunnel is located in a denudating hill zone. The absolute elevation of the tunnel is $60 \mathrm{~m}$, and the exposed stratum consists mainly of upper Jurassic crystal clast welded tuff (Figure 5). Due to the fact that the road which abuts the Ou River is located to the left of the tunnel and due to the fact that some houses are positioned on top of the hill, the settlement increment of the double arch tunnel becomes very important.

4.2. Main Stratum in Engineering Zone. According to their formation, lithology, characteristics, and weathering degree, the stratums were divided into following parts: (1) quaternary residual soil; (2) strong weathering crystal clast welded tuff; (3) weak weathering crystal clast welded tuff; and (4) slightly weathering crystal clast welded tuff.

4.3. Model and Interval Estimation. Figures 6, 7, 8, and 9 show the geometrical parameter models for the structural plane

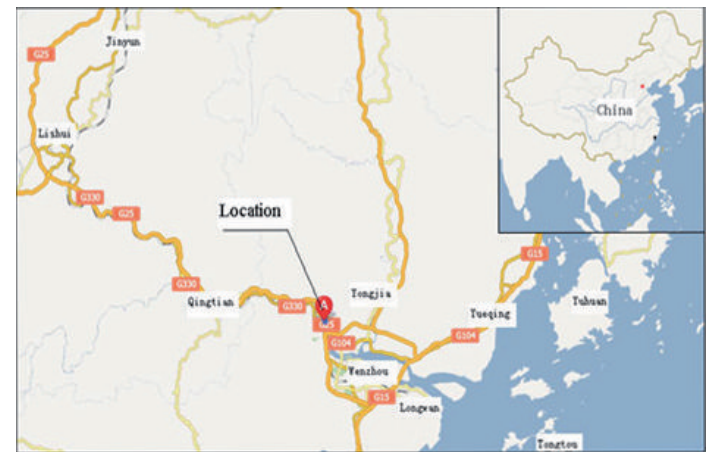

FIGURE 4: Location of engineering.

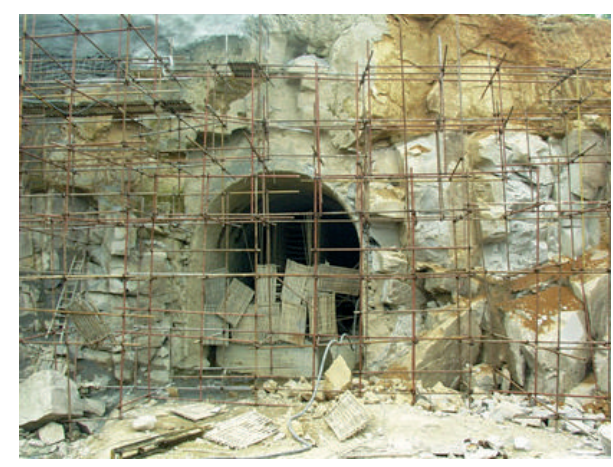

FIGURE 5: Hongfeng tunnel of Jinliwen expressway.

of the first group. From the figures, it may be seen that the models possess strong consistency in terms of orientation, spacing, and trace length of the structural plane. The normal and Weibull models for different geometrical parameters were defined by employing statistics and analysis of structural plane. The models were then used to define the confidence intervals of different geometrical parameters of structural plane.

According to the field data and construction models of the Hongfeng tunnel, the confidence intervals for each parameter of the various structural planes were constructed 
TABLE 3: Confidence intervals of geometrical parameters of structural plane in tunnel PD6.

\begin{tabular}{lcr}
\hline Parameters of structural plane & $95 \%$ & $\begin{array}{c}99 \% \\
\text { Scope of orientation }\end{array}$ \\
\hline Joint 1 & Scope of orientation & $78.61 \sim 81.37 / 78.17 \sim 81.80$ \\
Joint 2 & $22.36 \sim 28.86 / 21.33 \sim 29.89$ & $64.71 \sim 68.78 / 64.07 \sim 69.42$ \\
Bedding & $51.48 \sim 58.80 / 56.32 \sim 59.96$ & $19.32 \sim 22.75 / 19.47 \sim 23.19$ \\
Trace length & $59.48 \sim 66.42 / 58.39 \sim 67.52$ & $47.70 \sim 59.60$ \\
Spacing & $49.12 \sim 58.17$ & $16.25 \sim 21.45$ \\
\hline
\end{tabular}

TABLE 4: Results of wavelet neural network training data.

\begin{tabular}{lccccccccccccc}
\hline \multirow{2}{*}{ Samples } & \multicolumn{3}{c}{ Orientation } & Trace length & Spacing & \multicolumn{3}{c}{ Expected output } & & \multicolumn{3}{c}{ Actual output } \\
\hline & Joint 1 & Joint 2 & Bedding & & & & & & & & & \\
\hline 1 & $0.0 / 75.0$ & $25.0 / 20.0$ & $25.0 / 82.0$ & 7.0 & 33.0 & 1 & 0 & 0 & 0 & 0.9864 & 0.0107 & 0.0626 & 0.0001 \\
2 & $0.0 / 75.0$ & $40.0 / 10.0$ & $30.0 / 85.0$ & 5.0 & 15.0 & 1 & 0 & 0 & 0 & 0.9866 & 0.0106 & 0.0612 & 0.0001 \\
3 & $15.0 / 74.0$ & $38.0 / 17.0$ & $20.0 / 82.0$ & 7.0 & 32.0 & 1 & 0 & 0 & 0 & 0.9794 & 0.0222 & 0.0100 & 0.0006 \\
4 & $30.0 / 83.0$ & $45.0 / 15.0$ & $35.0 / 84.0$ & 13.0 & 14.0 & 0 & 1 & 0 & 0 & 0.0160 & 0.9617 & 0.0093 & 0.0351 \\
5 & $40.0 / 80.0$ & $25.0 / 30.0$ & $30.0 / 84.0$ & 10.0 & 14.0 & 0 & 0 & 0 & 1 & 0.0039 & 0.0586 & 0.0607 & 0.9275 \\
6 & $5.0 / 67.0$ & $50.0 / 21.0$ & $15.0 / 83.0$ & 90.0 & 54.0 & 1 & 0 & 0 & 0 & 0.9640 & 0.0210 & 0.4803 & 0.0002 \\
7 & $10.0 / 62.0$ & $35.0 / 16.0$ & $30.0 / 79.0$ & 30.0 & 27.0 & 1 & 0 & 0 & 0 & 0.9327 & 0.0357 & 0.0744 & 0.0001 \\
8 & $15.0 / 65.0$ & $20.0 / 35.0$ & $15.0 / 84.0$ & 106.0 & 45.0 & 0 & 0 & 1 & 0 & 0.0159 & 0.0047 & 0.9915 & 0.0564 \\
9 & $25.0 / 85.0$ & $20.0 / 22.0$ & $14.0 / 84.0$ & 80.0 & 30.0 & 0 & 0 & 1 & 0 & 0.0104 & 0.0049 & 0.9916 & 0.0592 \\
10 & $65.0 / 75.0$ & $36.0 / 21.0$ & $65.0 / 88.0$ & 52.0 & 14.0 & 0 & 0 & 1 & 0 & 0.0153 & 0.0058 & 0.9621 & 0.0566 \\
11 & $20.0 / 68.0$ & $30.0 / 15.0$ & $0.0 / 75.0$ & 55.0 & 15.0 & 0 & 0 & 1 & 0 & 0.0161 & 0.0048 & 0.9917 & 0.0566 \\
12 & $55.0 / 65.0$ & $26.0 / 20.0$ & $50.0 / 80.0$ & 70.0 & 12.0 & 0 & 0 & 1 & 0 & 0.0153 & 0.0057 & 0.9607 & 0.0526 \\
13 & $18.0 / 79.0$ & $25.0 / 18.0$ & $20.0 / 75.0$ & 26.0 & 8.0 & 0 & 0 & 1 & 0 & 0.0151 & 0.0057 & 0.9611 & 0.0518 \\
14 & $10.0 / 77.0$ & $20.0 / 18.0$ & $35.0 / 70.0$ & 36.0 & 9.0 & 0 & 0 & 1 & 0 & 0.0143 & 0.0054 & 0.9620 & 0.0496 \\
\hline
\end{tabular}

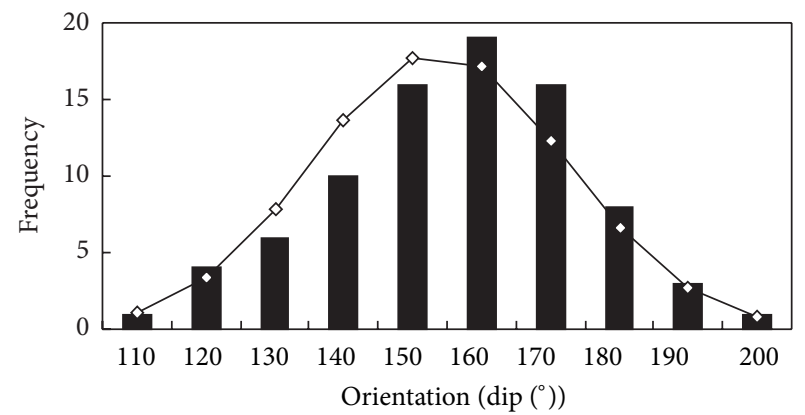

Frequency

FIGURE 6: Model of orientation (dip).

(Table 5). From Table 5, the confidence intervals of joints 1 and 2 were defined by using the method mentioned above. The bedding is statistic due to the lack of variant data and unity orientation. Therefore, the representative structural planes were chosen to define the confidence intervals.

4.4. Prediction of Wavelet Neural Network. The overbreak blocks occurring in the Hongfeng tunnel were predicted using the trained wavelet neural network. Table 6 shows the

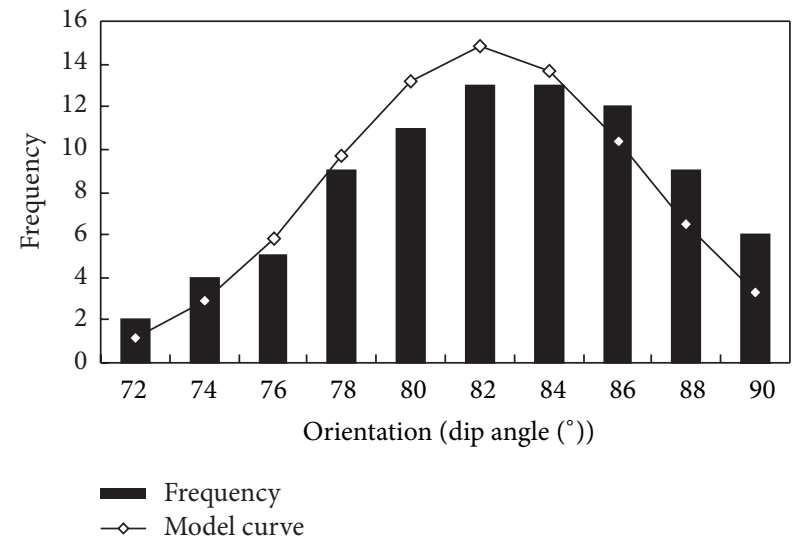

FIGURE 7: Model of orientation (dip angle).

volumes of the Hongfeng tunnel overbreak blocks obtained by using the wavelet neural network.

From Table 6, it may be seen that the prediction results coincide to $(0,0,0,1)$. The table shows that the volume of the Hongfeng tunnel is less than $0.05 \mathrm{~m}^{3}$. From the survey in the field, it is known that the structural plane persistence of the Hongfeng tunnel is well, but the connection of the structural plane is poor; thus, it is not possible to generate large overbreak blocks with volume greater than $0.05 \mathrm{~m}^{3}$, 
TABLE 5: Interval estimation for each parameter in the Hongfeng tunnel.

\begin{tabular}{lcccc}
\hline \multicolumn{2}{c}{ Structural plane } & \multicolumn{4}{c}{ Hongfeng tunnel } \\
Confidence level & Geometrical parameter & Joint 1 & Joint 2 & Bedding \\
\hline \multirow{3}{*}{$95 \%$} & Orientation $\left(^{\circ}\right)$ & $149.87 \sim 187.77 / 81.22 \sim 83.15$ & $54.12 \sim 61.72 / 81.78 \sim 83.75$ & $60.0 \sim 80.0 / 8.0 \sim 15.0$ \\
& Spacing $(\mathrm{cm})$ & $39.96 \sim 53.58$ & $29.36 \sim 62.18$ & $/$ \\
\hline & Trace length $(\mathrm{cm})$ & $53.20 \sim 82.80$ & $49.26 \sim 98.74$ & $/$ \\
$99 \%$ & Orientation $\left(^{\circ}\right)$ & $142.75 \sim 159.01 / 76.71 \sim 83.46$ & $47.43 \sim 62.92 / 77.43 \sim 84.06$ & $60.0 \sim 80.0 / 8.0 \sim 15.0$ \\
& Spacing $(\mathrm{cm})$ & $29.87 \sim 56.20$ & $26.79 \sim 67.33$ & $/$ \\
\hline
\end{tabular}

TABLE 6: Results of neural network prediction in the Hongfeng tunnel.

\begin{tabular}{|c|c|c|c|c|c|c|c|c|c|}
\hline \multirow[t]{2}{*}{ Samples } & \multicolumn{3}{|c|}{ Orientation } & \multirow[t]{2}{*}{ Trace length } & \multirow[t]{2}{*}{ Spacing } & \multicolumn{4}{|c|}{ Actual output } \\
\hline & Joint 1 & Joint 2 & Bedding & & & & & & \\
\hline 1 & $155.90 / 82.61$ & $57.48 / 81.87$ & $60.69 / 12.10$ & 55.77 & 41.03 & 0.0032 & 0.0326 & 0.0792 & 0.9843 \\
\hline 2 & $168.53 / 82.09$ & $60.36 / 82.47$ & $65.90 / 8.69$ & 66.10 & 50.74 & 0.0032 & 0.0322 & 0.0899 & 0.9844 \\
\hline 3 & $157.57 / 81.38$ & $58.77 / 83.04$ & $65.55 / 14.21$ & 60.62 & 43.37 & 0.0032 & 0.0322 & 0.0894 & 0.9844 \\
\hline 4 & $175.21 / 82.12$ & $61.59 / 83.45$ & $64.11 / 12.50$ & 69.08 & 49.54 & 0.0032 & 0.0322 & 0.0899 & 0.9844 \\
\hline 5 & $179.22 / 81.39$ & $56.82 / 82.59$ & $60.56 / 9.44$ & 55.34 & 45.32 & 0.0032 & 0.0322 & 0.0899 & 0.9844 \\
\hline
\end{tabular}

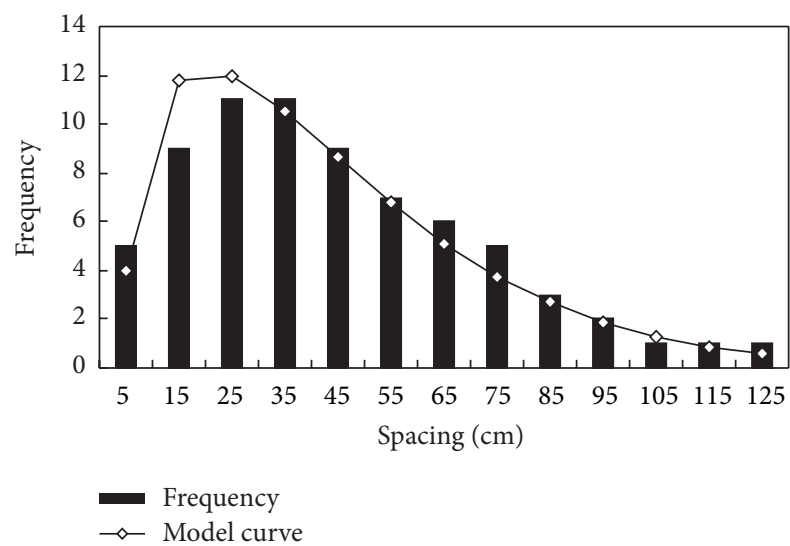

Figure 8: Model of spacing.

and only small overbreak blocks may appear on the surface of the tunnel. The results of the wavelet neural network prediction are obtained under the idealized intersection of the structural plane. During the excavation of the tunnel, different construction methods are used to reduce or avoid overbreak blocks according to the actual conditions.

\subsection{Field Survey and Analysis}

4.5.1. Field Survey. Figure 10 shows that the overbreak blocks appear on the left wall of the tunnel, and Figure 11 shows that the overbreak blocks appear on the top of the center wall in the double arch tunnel. From the two figures, it may be seen that the connection among the different structural planes is very strong. The overbreak blocks were caused by the intersection of the different structural planes, and the overbreak blocks are predominantly wedge-shaped.

In order to verify the results of the wavelet neural network, one section of the left side of the Hongfeng tunnel was chosen to be investigated in situ. The location of the

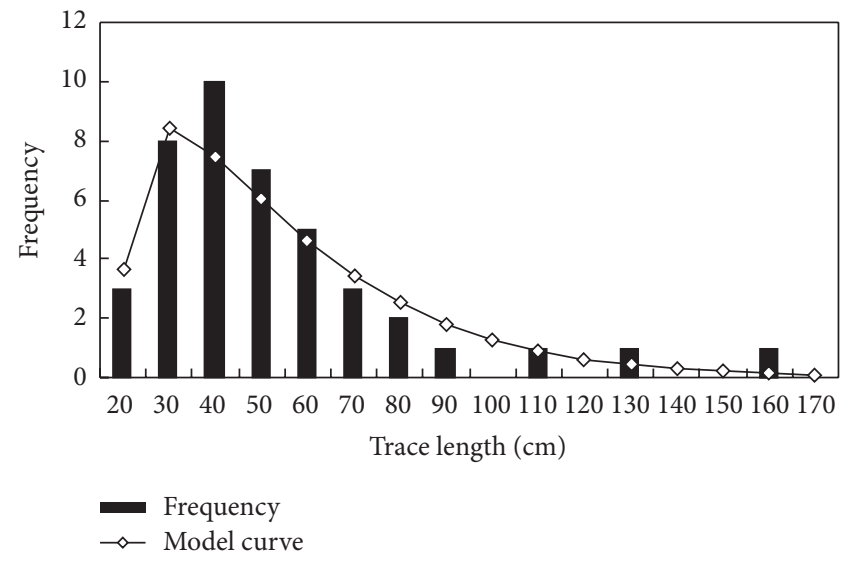

FIgURE 9: Model of trace length.

tunnel section was $\mathrm{k} 214+878 \sim \mathrm{k} 214+883$, and its length was $5 \mathrm{~m}$. The survey contents included the shape and size of all the overbreak blocks. The survey results are shown in the magnified image (Figure 12).

The size of the magnified view is $5 \times 17 \mathrm{~m}$, and the amount of overbreak blocks is 134 . From Figure 12, it may be seen that the overbreak blocks appear on the side of the center and left walls of the tunnel, where the projected geometrical shape of the left wall is regular. It shows that the overbreak blocks are affected by the geological structure, construction, and shape of the tunnel. The structural planes of the three groups are steep dip angles, which is an advantageous condition to forming these overbreak blocks.

4.5.2. Projection Distribution Character of Overbreak Blocks. The numerical results of the overbreak blocks are shown in the form of a histogram in Figure 13. The statistics show that the average area of the overbreak blocks is $0.22 \mathrm{~m}^{2}$, the 


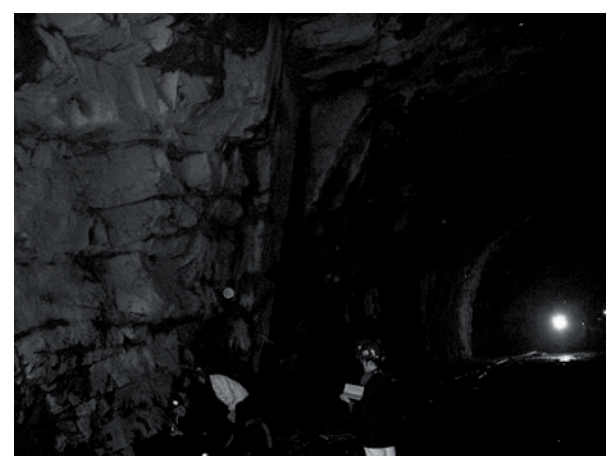

FIGURE 10: Overbreak blocks on the left wall of the tunnel.

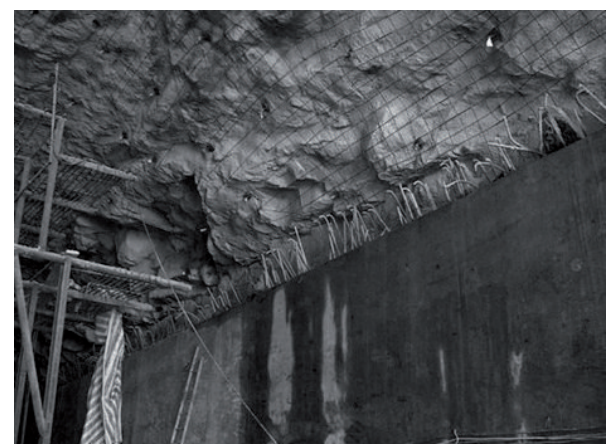

FIGURE 11: Overbreak blocks on the top of the center wall.

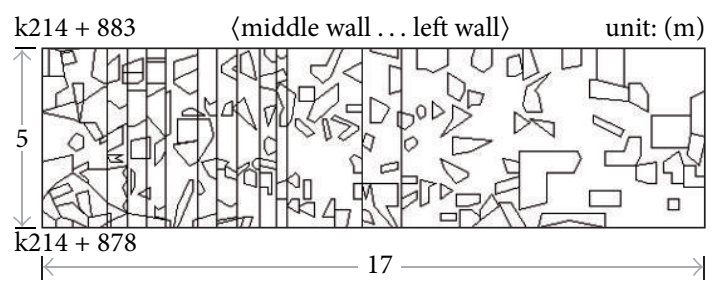

FIGURE 12: Projected magnified view of overbreak blocks of the tunnel section $\mathrm{k} 214+878 \sim 883$.

minimum area is $0.03 \mathrm{~m}^{2}$, and the maximum area is $1.54 \mathrm{~m}^{2}$. There are 115 overbreak blocks distributed between 0.04 and $0.36 \mathrm{~m}^{2}$, accounting for $85.8 \%$ of all overbreak bocks. The area distribution figure is consistent with the Weibull model. The value of the $\chi^{2}$ is 12.01, which approaches the corresponding critical value of 13.28 (freedom is $4, \alpha=0.01$ ). The curve shown in Figure 13 is the Weibull model. The average area of the projection is $0.22 \mathrm{~m}^{2}$.

4.5.3. Overbreak Blocks Volume Distribution Characters. The respective volumes of the overbreak blocks are evaluated by their projection area and average depth. Irregular overbreak blocks are changed to their equivalent irregular shape. The volume of each overbreak block is calculated by this method. Figure 14 illustrates the cross distribution of the respective volumes of the overbreak blocks. The statistics show that the average volume of the overbreak blocks is $0.03 \mathrm{~m}^{3}$, minimum area is $0.002 \mathrm{~m}^{3}$, and maximum area is $0.285 \mathrm{~m}^{3}$. As far as

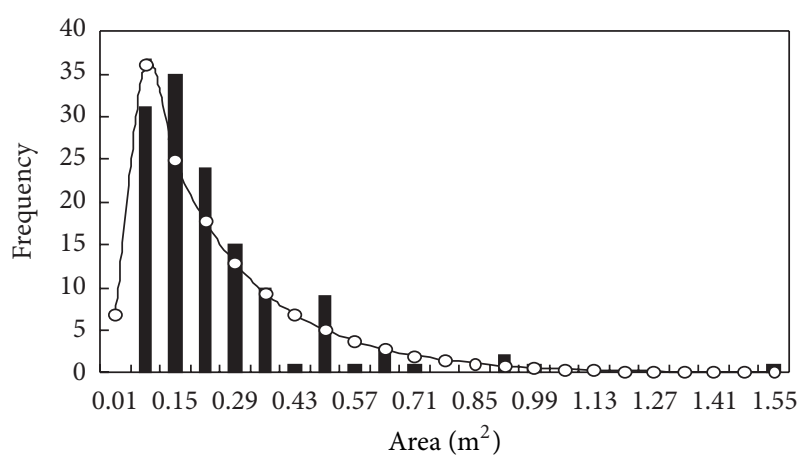

FIGURE 13: Area distribution model of overbreak blocks projection.

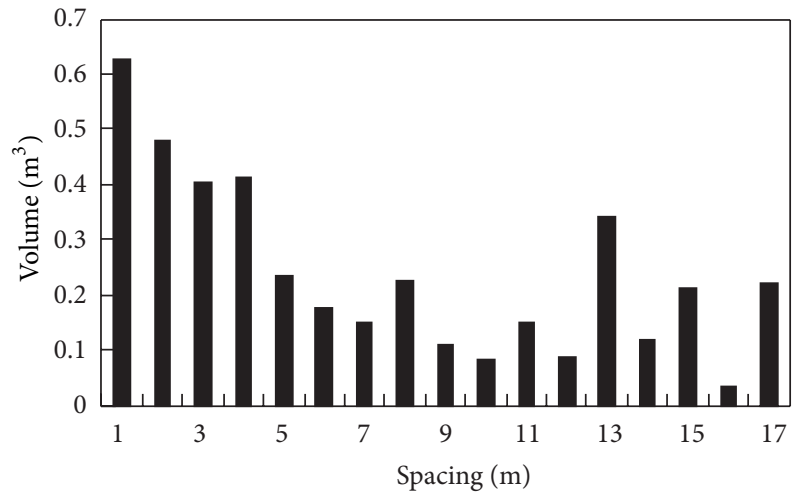

FIgURE 14: Overbreak blocks cross volume distribution.

average volume of overbreak blocks the concerned, there exists is an approximate $10 \% \sim 30 \%$ difference between the prediction and the real volume of overbreak blocks. The volume of overbreak blocks of the entire survey zone is $4.071 \mathrm{~m}^{3}$, and the volumes of overbreak blocks is $0.814 \mathrm{~m}^{3}$ in unit width.

Figure 14 shows the gradual decrease of the section between 1.0 and $12.0 \mathrm{~m}$. The curve becomes steep at the $13.0 \mathrm{~m}$ point. The volumes of the overbreak blocks, which are controlled by the structural plane, increase in size. The scope of the largest volume of the overbreak blocks is $0.0-1.0 \mathrm{~m}$, and the volume of the largest overbreak block is $0.627 \mathrm{~m}^{3}$. The scope of the smallest volume of the overbreak block is $15.0-16.0 \mathrm{~m}$, and the volume of the largest overbreak block is $0.036 \mathrm{~m}^{3}$. According to the construction character of the double arch tunnel, the excavation of the center tunnel will cause the surrounding rock to loosen. After the excavation of the two lateral tunnels, severe overbreak occurred on top of the center tunnel. Field survey shows that the effect scope of surrounding rock loosening in the center tunnel excavation is $1.0-4.0 \mathrm{~m}$. The corresponding elevation section of the left side of the left tunnel is $9.5-12.5 \mathrm{~m}$. The total volume of overbreak block is $1.923 \mathrm{~m}^{3}$ from 1.0 to $4.0 \mathrm{~m}$ section, and its volume is $0.365 \mathrm{~m}^{3}$ from 9.5 to $12.5 \mathrm{~m}$. The difference between the two sections is $1.558 \mathrm{~m}^{3}$, and the unit difference volumes are $0.312 \mathrm{~m}^{3}$, occupying $38.33 \%$ of all unit overbreak. It is possible that the overbreak difference was caused by the loosening 


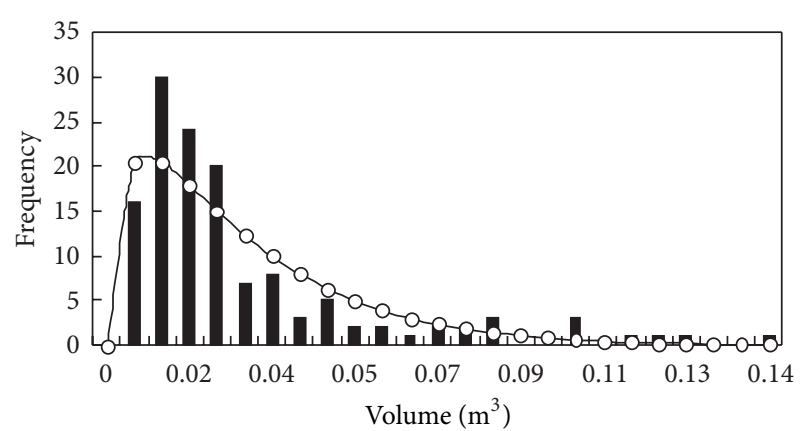

FIGURE 15: Volume distribution and model of the overbreak blocks.

of the surrounding rock during the excavation of the center tunnel.

From the volume distribution character, it may be seen that the figures are consistent with the Weibull model. The value of the $\chi^{2}$ is 15.50 , which is less than the corresponding critical value, and the critical value is 16.81 (freedom is $6, \alpha=$ 0.01). The curve in Figure 15 represents the Weibull model.

To sum up, the projection areas of the overbreak blocks are mainly quadrilateral, pentagonal, and hexagonal in shape, and its main perimeters are $1.37-2.30 \mathrm{~m}$. The distribution model is logarithmically normal model. The average area of the overbreak blocks is $0.22 \mathrm{~m}^{2}$, and its area is mainly distributed from 0.04 to $0.36 \mathrm{~m}^{2}$. The distribution model is the Weibull model. The average volume of the overbreak blocks is $0.03 \mathrm{~m}^{3}$. The unit width volume of the overbreak blocks is $0.81 \mathrm{~m}^{3}$. The volume distribution model is the Weibull model. The volume of its unit width overbreak blocks is $0.31 \mathrm{~m}^{3}$ due to the loosening of the surrounding rock on the top of the center tunnel, occupying $38.33 \%$ of all unit overbreak.

\section{Conclusions}

By means of geological geometry parameters survey of the Hongfeng tunnel, on the Jinliwen Expressway, located in Zhejiang province, China, the structural plane geometry parameters were statistically analyzed, and the corresponding distribution models were obtained. The overbreak blocks occurring in the Hongfeng tunnel were predicted by analyzing the structural plane geometrical characteristic parameters. The study results were achieved by surveying the volume and the shape of the overbreak blocks in the Hongfeng tunnel and by comparing the prediction results by adopting the wavelet neural network.

(1) From the survey result in the field, it was seen that there were three groups of structural planes in the Hongfeng tunnel. As was verified from the calculation results and survey in the field, it was shown that the bedding has great effects on the overbreak blocks occurring in the tunnel.

(2) The orientation, spacing, and trace length of the structural plane were considered in the wavelet neural network. From the calculation results, it was seen that the volume of the overbreak blocks in the Hongfeng tunnel was less than $0.05 \mathrm{~m}^{3}$. The combination of the structural plane and excavation method of the Hongfeng tunnel directly affected the volumes of overbreak blocks. During the construction of the tunnel, the combination of the structural plane and probability of disadvantage combination must be predicted properly. Under certain geological conditions, different excavation methods need to be adopted in order to decrease the occurrence of overbreak blocks.

(3) From the predicted results and survey results in the field, it may be seen that the location of overbreak blocks in the Hongfeng tunnel is the left wall of the left tunnel. This is concordant with the calculation results and shows that the proposed overbreak blocks prediction method may be used to effectively predict the overbreak of the tunnel.

(4) The results of the overbreak block prediction show that the wavelet neural network may be used to predict overbreak in the tunnel. The method utilizes the superiority of the nonlinear construction model of the wavelet neural network, and the results show that this method may indeed satisfy the requirements of overbreak blocks prediction.

\section{Acknowledgments}

This paper is jointly supported by the National Natural Science Foundation of China (no. 41002089 and 41102162) and the National Key Technology R\&D Program in the 11th Five-Year Plan of China (2008BAB29B03).

\section{References}

[1] W. Jimin and A. Mahtab, "Opening overbreak forecasting of jointed rock mass," Journal of Engineering Geology, vol. 7, no. 1, pp. 3-8, 1999.

[2] Z. Jiamei, G. Bo, and L. Zhiye, "Effects of overbreak and underbreak in tunnels on surrounding rock and support structure by means of TBM excavation," Underground Space, vol. 23, no. 2, pp. 124-127, 2003.

[3] S. Jian and Z. Xinjiao, "Research on statistics rules of road tunnel overbreak and underbreak," Journal of Chongqing Communication College, vol. 19, no. 2, pp. 15-20, 2000.

[4] Y. Deyun, "Section area calculation of tunnel overbreak and underbreak," Journal of Shandong Science and Technology, vol. 19, no. 2, pp. 76-78, 2000.

[5] Z. Huibing, "Research on statistical rules of tunnel overbreak and underbreak under drill hole blasting," Journal of Railway Engineering, vol. 16, no. 3, pp. 106-110, 1999.

[6] W. Mingnian and G. Baoshu, "Research on tunnel stability affected by overbreak and underbreak by means of the selfadaption finite element method," Underground Space, vol. 16, no. 1, pp. 12-19, 1999.

[7] G. F. Revey, "Effects and control of overbreak in underground mining," Mining Engineering, vol. 50, no. 8, pp. 63-67, 1998.

[8] J. A. Ibarra, N. H. Maerz, and J. A. Franklin, "Overbreak and underbreak in underground openings Part 2: causes and 
implications," Geotechnical and Geological Engineering, vol. 14, no. 4, pp. 325-340, 1996.

[9] N. H. Maerz, J. A. Ibarra, and J. A. Franklin, "Overbreak and underbreak in underground openings Part 1: measurement using the light sectioning method and digital image processing," Geotechnical and Geological Engineering, vol. 14, no. 4, pp. 307323, 1996.

[10] J. A. Franklin, J. T. Ibarra, and N. H. Maerz, "Blast overbreak measurement by light sectioning," International Journal of Mining and Geological Engineering, vol. 7, no. 4, pp. 323-331, 1989.

[11] A. Thidemann, "The influence of cracking on overbreak at tunneling," Fjellsprengningsteknikk, Bergmekanikk/Geoteknikk, Oslo, Norway, pp. 191-199, 1976.

[12] J. F. Abel, Average Percentage of Overbreak Beyond Payment Line, MN-461 Course Notes, Colorado School of Mines, Golden, Colo, USA, 1982.

[13] J. Martna, "Selective overbreak in the Suorva-Vietas tunnel cased by rock pressure," in Proceeding of the International Symposium on Underground Openings, pp. 141-145, Lucerne, Switzerland, 1972.

[14] R. E. Goodman, "Block theory and its application," Geotechnique, vol. 45, no. 3, pp. 383-423, 1995. 


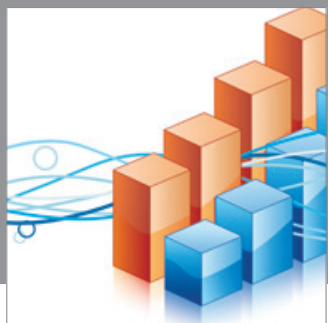

Advances in

Operations Research

mansans

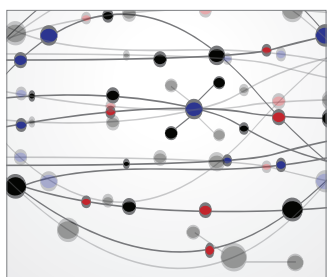

The Scientific World Journal
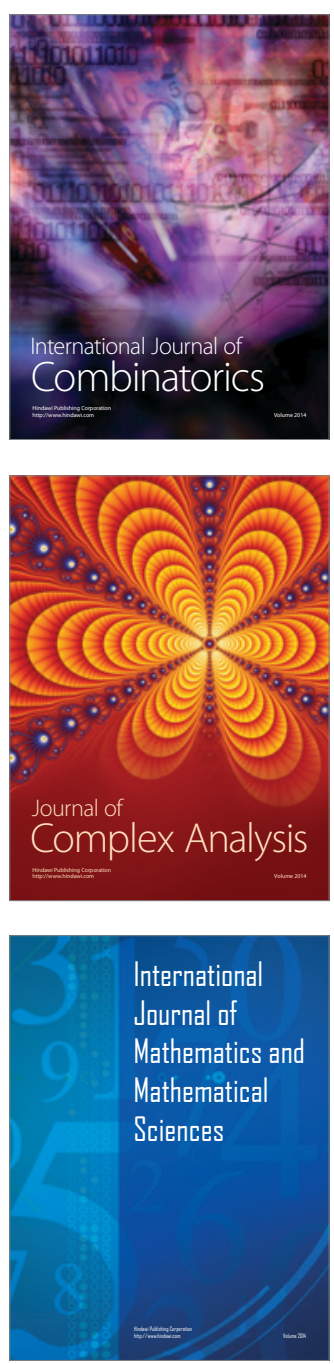
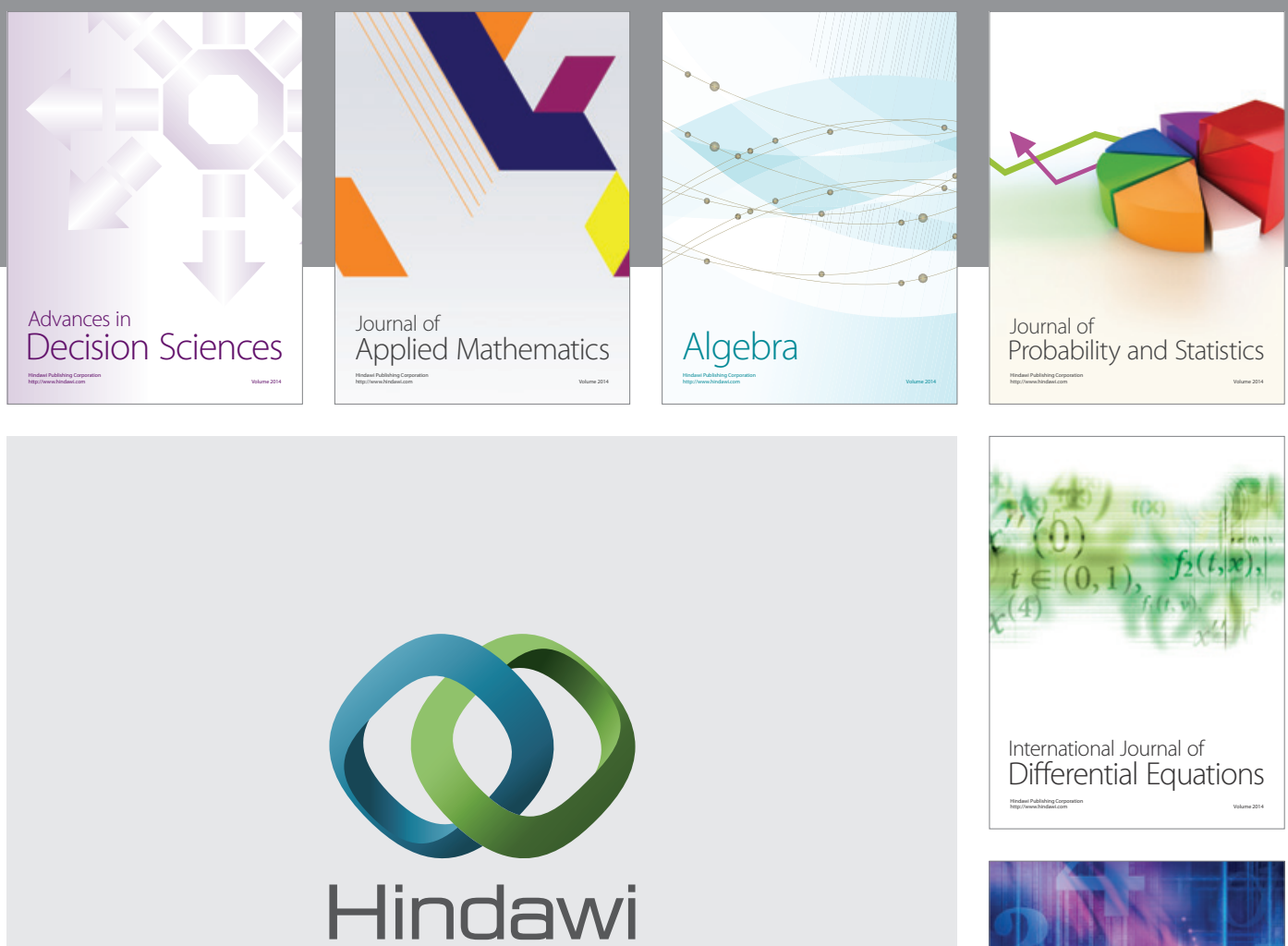

Submit your manuscripts at http://www.hindawi.com
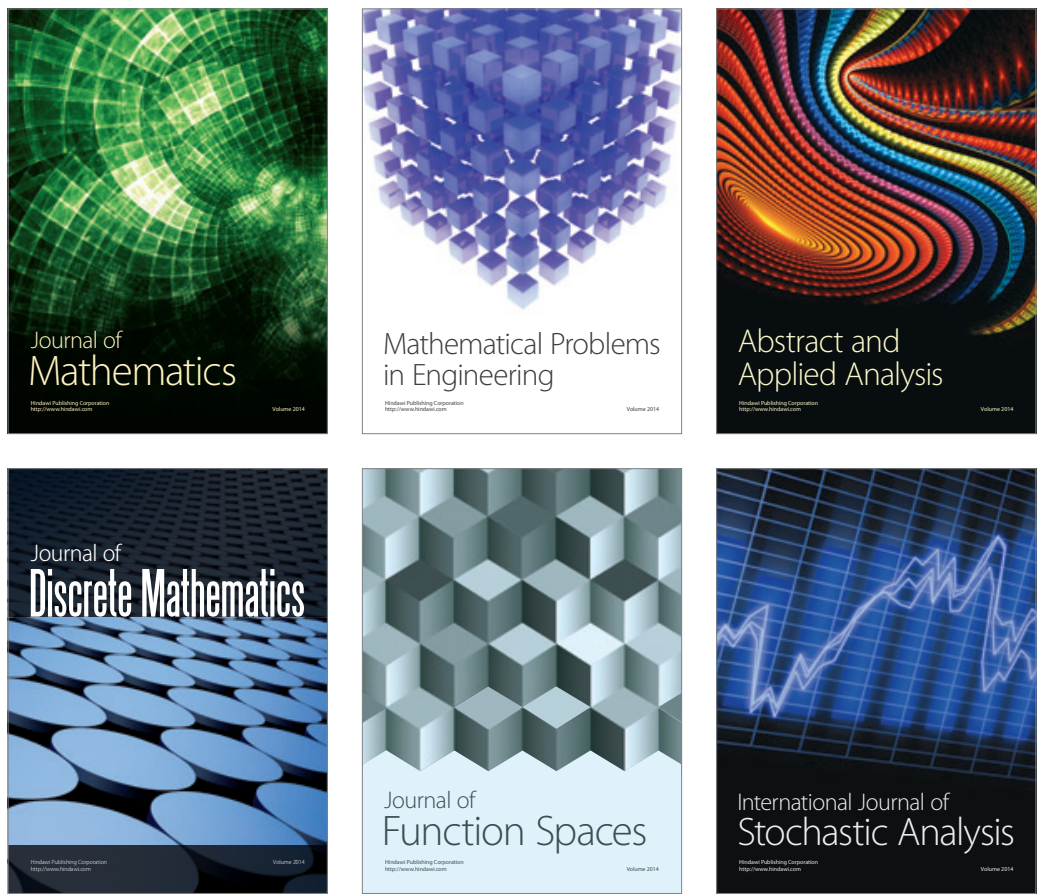

Journal of

Function Spaces

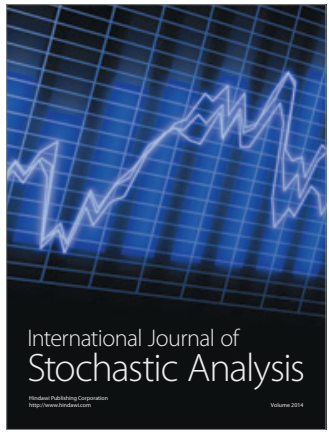

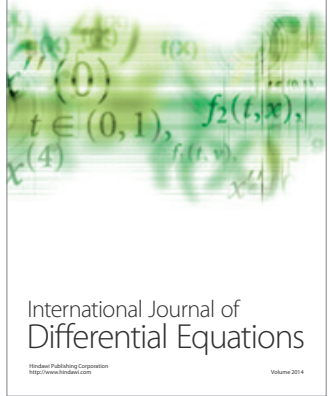
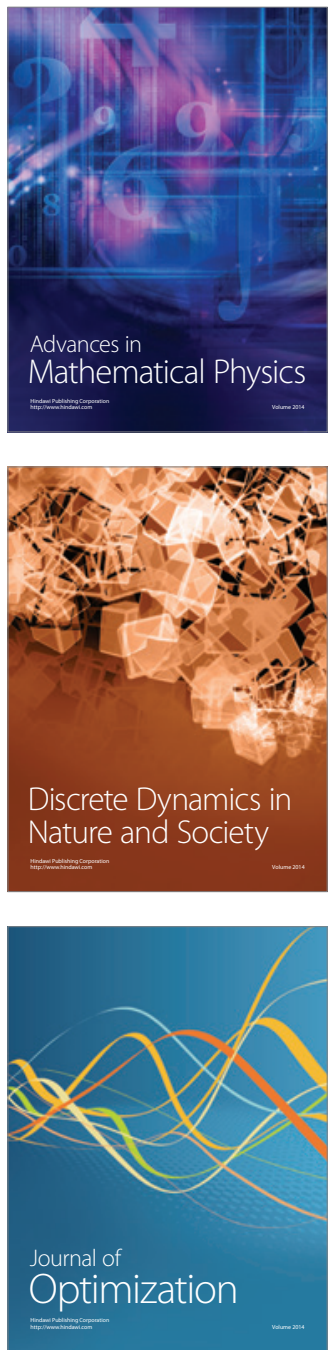